\section{Comment on paper by Mitchell, Scott, and Mitchell}

\section{JAMES C. SMITH \\ Florida State University, Tallahassee, Florida 32306}

I have read with interest the paper by Mitchell et al. (1977) and the subsequent correspondence regarding this paper (Mitchell, 1977; Revusky, 1977). There are several points missing from the paper and the correspondence which need attention. I submit evidence from our past research for consideration.

We conducted several X-ray-induced tasteaversion studies using groups of rats where saccharin was paired with $\mathrm{X}$-rays, saccharin was paired with sham exposure, water was paired with X-rays, or water was paired with sham exposure (e.g., Morris \& Smith, 1964; Smith \& Birkle, 1966; Smith \& Morris, 1964; Smith, Morris, \& Hendricks, 1964; Smith \& Schaeffer, 1967). Always using a 24-48 two-bottle preference test, always analyzing preference scores and total fluid consumption, we found aversion in the saccharin-X-ray groups and no significant aversion in the other groups. Sometimes there was more variability in water-X-ray groups (Smith, et al. 1964, is an example of this-see Table 1), but these water-X-ray groups were not different from the water-sham groups.

Later, Scarborough's group (e.g., McLaurin, Farley, Scarborough, \& Rawlings, 1964; McLaurin \& Scarborough, 1963; McLaurin, Scarborough, \& Farley, 1964; Scarborough \& McLaurin, 1964), began reporting taste aversions in water-X-ray groups. These results were puzzling to us for some time, but we think we subsequently understood his group's findings. In the Scarborough studies, the preference test was started immediately following the pairing of saccharin or water with X-ray. Therefore, we assumed that the aversion consequences of the X-rays were being paired with the saccharin available in the preference test. I think the paper by Schaeffer and me (1967) showed that assumption was correct. Once again, we saw no conditioning in water-X-ray or empty bottle-X-ray groups.

Mitchell et al. (1977) correctly state that Roll and I (1967) did not include noncontingently poisoned controls in our experiment, i.e., rats receiving water-X-ray treatment or no solution X-ray treatment. We did not because there was such a history in our laboratory of that control group's showing no evidence of conditioning. In retrospect, if we had run the noncontingent control group I don't believe our conclusions would have differed because we used a two-bottle 48-h preference test and one can see no effects of neophobia or enhanced neophobia with that preference measure (see Carroll, Dinc, Levy, \& Smith, 1975). I am convinced that some confusion in the taste aversion literature results from the differences between a short-term single-bottle test and the long-term two-bottle test.

Where are we? I conclude that the noncontingent controls mean much if the test is a short-term test where neophobia and enhanced neophobia are evident and that the noncontingent controls mean little if the preference test is a long-term one (Carroll et al., 1975). I think that a group of the noncontingent controls in the Smith and Roll (1967) study would not change the results of that experiment. That control group has not been run under these circumstances, but since one gets no aversion in "water-X-ray immediate groups," it seems fruitless to look for aversion in "water-X-ray delay groups" as long as the aversion test is the long-term twobottle preference test. I cannot, therefore, agree that there has been a "general failure to appreciate the importance of nonassociative factors in delayed poisoning taste-aversion experiments." I am convinced that nonassociative factors do not matter when a long-term test is used.

A few other points may be worth mentioning. I do not know the evidence for the statement in the Mitchell letter (1977), "There is little doubt that animals exposed to $\mathrm{X}$-rays of this magnitude, especially the higher dose (which is approximately one half of the $\mathrm{LD}_{50}$ ), remain 'sick' for several days following treatment (as evidenced by prolonged hypophagia)." We have seen no evidence of "sickness" in a rat $6 \mathrm{~h}$ following X-ray exposure. I have seen no prolonged hypophagia, and there is considerable evidence that intakes of saccharin and water are not modified (see Barker \& Smith, 1974, Figure 1, page 647). Also, the $\mathrm{LD}_{50}$ for a rat is $750 \mathrm{R}$, three times the exposure Revusky (1968) used.

Although Roll and I reported evidence of taste aversion with 12-h CS-US delays, I think the more realistic figure is from the Barker and Smith (1974) paper. In the Barker and Smith paper, we did not see significant evidence of taste aversion beyond the 6-h delay group. A 6-h delay in the Mitchell et al. (1977) study may be too long to clearly demonstrate their point. I would like to see intermediate groups added to the Mitchell et al. (1977) paper. There should be an orderly change in the extinction curves between the P-Soc-I and the P-Soc-D groups.

The tests in Revusky's (1968) and Mitchell et al. (1977) papers were short-term tests. I do not understand why the irradiated or poisoned controls did not show any enhanced neophobia. I would suspect the previous experience [not the "size of the group" as suggested by Mitchell (1977)] made some difer- 
ence in Revusky's study. He did have 10 control subjects, and their mean was higher than .80 , allowing little room for variability.

\section{REFERENCES}

BaKer, L. M., \& SMITh, J. C. A comparison of taste aversions induced by radiation and lithium chloride in CS-US and US-CS paradigms. Journal of Comparative and Physiological Psychology, 1974, 97, 644-654.

Carroll, M. E., Dinc, H. I., Levy, C. J., \& SMith, J. C. Demonstrations of neophobia and enhanced neophobia in the albino rat. Journal of Comparative and Physiological Psychology, 1975, 89, 457-467.

Mclaurin, W. A., Farley, J. A., Scarborough, B. B., \& Rawlings, T. D. Post-irradiation saccharin avoidance with non-coincident stimuli. Psychological Reports, 1964, 14, 507-512.

McLaurin, W. A., \& Scarborough, B. B. Extension to the interstimulus interval in saccharin avoidance conditioning. Radiation Research, 1963, 20, 317-324.

Mclaurin, W. A., Scarborough, B. B., \& Farley, J. A. Delay of post-irradiation test fluids: $A$ factor in avoidance behavior. Radiation Research, 1964, 22, 45-52.

Mrtchell, D. Reply to Revusky. Animal Learning \& Behavior, 1977, 5, 321-322.

Mrtchell, D., Scott, D. W., \& Mrchell, L. K. Attenuated and enhanced neophobia in the taste-aversion "delay of reinforcement" effect. Animal Learning \& Behavior, 1977, 5, 99-102.

MoRRIS, D. D., \& SMTrH, J. C. X-ray conditioned saccharin aversion induced during the immediate postexposure period. Radiation Research, 1964, 21, 513-519.

Revusky, S. H. Aversion to sucrose produced by contingent $\mathrm{x}$-irradiation. Journal of Comparative and Physiological Psychology, 1968, 65, 17.22.

Revusky, S. H. Correction of a paper by Mitchell, Scott, and Mitchell. Animal Learning \& Behavior, 1977, 5, 320.

Scarborough, B. B., \& McLaurin, W. A. Saccharin avoidance conditioning instigated immediately after the exposure period. Radiation Research, 1964, 21, 299-307.

Smith, J. C., \& BirkLe, R. A. Conditioned aversion to sucrose in rats using $\mathrm{X}$-rays as the unconditioned stimulus. Psychonomic Science, 1966, 5, 271-272.

SMITH, J. C., \& MoRRIs, D. D. The effects of atropine sulfate and physostigmine on the conditioned aversion to saccharin solution with X-rays as the unconditioned stimulus. In T. J. Haley \& R. S. Snider (Eds.), Response of the nervous system to ionizing radiation. New York: Little, Brown, 1964.

Smith, J. C., Morris, D. D., \& Hendricks, J. Conditioned aversion to saccharin solution with high dose rates of $X$-rays as the unconditioned stimulus. Radiation Research, 1964, 22, 507-510.

SmIth, J. C., \& Roll, D. L. Trace conditioning with X-rays as an aversive stimulus. Psychonomic Science, 1967, 9, 11-12.

Smith, J. C., \& Schaeffer, R. W. Development of water and saccharin preferences after simultaneous exposures to saccharin solution and gamma rays. Journal of Comparative and Physiological Psychology, 1967, 63, 434-438.

(Received for publication June 30, 1977; revision accepted October $20,1977$. 